\title{
Creating a Counter-Space through Listening to and Learning from a Korean Pre-service Teacher's Experiences
}

\author{
Jihea Kang (Corresponding author) \\ Dept. of Curriculum Instruction and Teacher Education, Michigan State University \\ Erickson Hall, 620 Farm Lane, East Lansing, MI 48824, USA \\ Tel: 1-734-827-4509Ｅ-mail: kangji5@msu.edu
}

\author{
Received: February 15, 2017 Accepted: April 2, $2017 \quad$ Published: April 5, 2017 \\ doi:10.5296/jei.v3i1.10756 URL: https://doi.org/10.5296/jei.v3i1.10756
}

\begin{abstract}
The author uses a life-historical counter-storytelling approach to examine a Korean female pre-service teacher's experiences in a U.S. teacher preparation program. The participant encountered challenges due to her perceived language proficiency and communication and participation style in a U.S. higher educational context. Further, the author report how the participant responded to her challenges: (1) by feeling pressure to internalize deficit-oriented narratives and assimilate into dominant cultural norms, and (2) by resisting against the racial stereotype. This study shows that teacher educators need to create counter-spaces for linguistic and ethnic/racial minority pre-service teachers in teacher preparation.
\end{abstract}

Keywords: International pre-service teachers, Racialized experiences, Counter-space, Counter-storytelling, Teacher preparation for diverse teacher candidates

\section{Introduction}

Ever greater numbers of students from Asian countries (e.g., China, Korea, India) have been enrolling in Western universities in English-speaking countries, such as Australia, Canada, and the U.S. (Campbell \& Li, 2008; Ryan, 2011; Tran \& Nguyen, 2015). In contrast to the growing research literature on the learning experiences and challenges faced by Asian international college students, reports on Asian international pre-service teachers' experiences in the field of teacher education are scarce. Echoing the experiences and needs of many internationally-educated immigrant teachers from culturally and linguistically diverse backgrounds, international pre-service teachers are expected to adjust themselves to a host country's cultural norms, local knowledge, school cultures and teaching practice (Lee, 2015; 
Santoro, 2009; Subedi, 2008). Studies indicate that international pre-service teachers mostly do well in their university coursework, yet face challenges during their practicum (Goodwin, 2010). For example, they often find it difficult to be established as legitimate teacher figures in the eyes of their students, colleagues, and families without sufficient professional support (Marom \& Ilieva, 2016).

Research indicates strong correlations among academic achievement of culturally and linguistically diverse students, teachers' understandings and knowledge of their students, and shared intercultural communications (Villegas \& Lucas, 2002). Furthermore, studies of dominant teacher candidate demographics (i.e., white, monolingual, middle-class, female) indicate that those pre-service teachers' predispositions, past experiences, and perspectives on diversity profoundly influence teaching practice during the practicum (Sleeter \& Owuor, 2011), professional growth (Santoro, 2009), and students' learning (Howard \& Aleman, 2008). Despite the increasing number of Asian international teacher candidates in teacher education programs, there is still a gap in understanding how Asian pre-service teachers, as a linguistic and ethnic/racial minority in teacher education, encounter and respond to challenges, if any, during teacher preparation.

\section{Discursive Construction of Non-Native Student Teachers}

One challenge that many non-native English-speaking teachers, including immigrant teachers and international teacher candidates, face is the myth of the native-speaking teacher in learning and teaching (Aneja, 2016). Diniz de Figueiredo (2011) examined the pervasive notion that native English speakers are better teachers, and the impact of this myth on institutional policies, employment, and practices (see also Canagarajah, 1999). This study addressed immigrant teachers' concerns prior to coming to the U.S., their experiences at school, and the role of language in their teaching. The findings illustrate that non-native English speaking teachers often feel insecure, to some extent. The participants initially found teaching intimidating due to the pervasive belief that native speakers are more authentic teachers of the English language. Nonetheless, teachers' professional identities go beyond authority and knowledge of language. There are other qualities important in developing professional identities, such as the capacity to build rapport with students, parents, and colleagues of various language backgrounds. However, the teachers' professional agency and self-assurance are still in constant tension due to the prevalent notion of native English-speakers superiority in teaching English. Kubota and Lin $(2006,2010)$ noted that we should move beyond the dichotomy of non-native versus native teachers in relation to perceived language proficiency or linguistic skills. Non-native English speakers (NNEST) Movement in the field of Teaching English to Speakers of Other Languages (TESOL) also highlights the significance of advocating for non-native English speaking teachers' capacity and self-efficacy.

Unfortunately, discrimination due to the native speaker fallacy is a common theme in reports of international Asian students' experiences (S. A. Kim \& R. H. Kim, 2010). Particularly, studies have reported that Asian international students are perceived to be quiet because they cannot speak English, or at least cannot speak it that well (Lippi-Green, 2012). However, 
focusing on their language barrier as the cause of their challenges positions these students as the Other. Thus, this view highlights dominant groups of students and instructors as neutral. While many Asian international students report being perceived as unintelligent due to their perceived language proficiency, they also experience the stereotypical perceptions of Asians as a model minority-passive, feminine, studious, hard-working, quiet (Ngo \& Lee, 2007). While research in higher education increasingly addresses the racialized experiences of international Asian students, the generic depiction of their experiences without any specific focus on their academic interests and professional experiences in a host country can be one way to construct them as cultural and linguistic outsiders who are invisible and voiceless. Research on international pre-service teachers' teacher preparation and challenges also highlights the need for systematic institutional support for diverse teachers in order to improve the educational experiences of all diverse students and teachers.

I recount the narrative told by a Korean female preservice teacher, Sumi (pseudonym), who was certified in a U.S. teacher preparation program and finished her practicum in an urban school context. This study describes her educational and cultural backgrounds, as well as her encounter with racialization and her responses during teacher preparation. It is important to note that I do not intend to essentialize international Asian pre-service teachers' experiences based on race/ethnicity, nationality and geographic origin. Rather, I counter that "Asian" international preservice teachers are by no means a homogeneous group. I also acknowledge that it is important to account for the multiple social identities that Asian international pre-service teachers may hold. Sumi's (counter-) stories resonate with diverse teacher candidates that extends beyond a particular linguistic or racial/ethnic group. Close listening to Sumi's (counter-) stories allows us to better understand, teach, recruit, and retain a diverse teaching force in the field of teacher education.

\section{Method}

\subsection{Voices through Oral Life History and Counter-Story Telling}

Elements of oral life histories and counter stories through interviews were used for two reasons. First, counter-storytelling values narratives as a means of expressing, understanding, and articulating one's marginalized experiences. According to Delgado and Stefancic (2012), through storytelling and counter-storytelling, hegemonic assumptions about marginalized people can be challenged. Because storytelling and fiction serve a valid and powerful function in deconstructing, constructing, and/or reconstructing embedded biases that marginalize the Other, counter-storytelling in the Critical Race Theory (CRT) approach is a powerful way to challenge mainstream assumptions about the participants in this study. Capturing counter-stories of the participants was also a tool to identify certain types of participants' experiences with micro-aggressive discrimination, and it gave participants power to end their silence and silencing. As Delgado and Stefancic (2012) illustrate, counter-narratives "provide a language to bridge the gaps in imagination and conception that give rise to the different" (p. 771).

Further, autobiographical narratives based on the participant's life history has the potential to help participants deepen one's understanding of their racialized experiences in order to make 
sense of those experiences during teacher preparation. Life history research largely focuses on a written or oral account of a life, or the partial segment of a life, as told by an individual. Understanding individual lives/stories is at the center of the research process and is a product of life history research (Cole \& Knowles, 2001). The oral life history and counter-storytelling approach enable us to understand the participants' lived experiences and to uncover patterns in the ways in which they are perceived and positioned on campus and in their professional lives. Further, using a life history approach and counter-stories allowed us to consider how researchers and teacher educators might alleviate the challenges encountered by language and ethnic/racial minority teacher candidates.

\subsection{Context}

The teacher education program in this study is in a major research state institution in the Midwestern United States. Drawing from a larger pilot study, participants were selected from those who (1) self-identified as international Asian students, (2) qualified as pre-service teachers for more than three years, and (3) speak other language(s) in addition to English. Through email and face-to-face conversations, two participants were selected by asking field instruction coordinators and instructors for recommendations. This article draws particularly on the experience of Sumi (pseudonym). Despite the similarities among participants in their length of study, areas of majors, or career goals, Sumi in particular illustrated her challenges in relation to her cultural, racial, and linguistic backgrounds during her field experiences and demonstrated critical reflections and professional growth. Her fieldwork placement school had an increasing number of culturally, linguistically, and racially diverse students whereas the teacher demographics were less diversified. Sumi was the only Asian teacher at school. Thus, her case provides opportunities to understand the nuanced challenges those teacher candidates from diverse backgrounds face in learning to teach during practicum as well as pose questions for further study. The institutional Ethics Committee granted ethical approval and participant gave informed consent.

\subsection{Participant}

At the time of the study, Sumi was a twenty-two-year old female Korean student. She majored in elementary education with a focus on language arts and minored in TESOL. She grew up with her parents and her older brother in Seoul, South Korea, until she went to a high school in the Philippines, as her aunt runs an English education study-abroad business between South Korea and the Philippines. Sumi comes from an upper middle class family background. She shared that she was raised and educated in Korea to be a studious person. Her parents encouraged her to study abroad in the U.S. to learn English and gain inter-cultural perspectives. Sumi chose to study education due to her passion for children as well as the strong reputation of the teacher preparation program at her university.

\subsection{Data Collection}

I started to have formal and informal conversations about Sumi's experiences during the spring semester of 2015. The qualitative data were gathered using:

- Four formal teaching observations during Sumi's lead teaching, which investigated 
narratives of her learning moments, and key incidents shaping her learning and learning to experiences during her field experiences.

- Two formal observations of fieldwork seminars that Sumi took, which examined relational and interactional challenges among her peers and field instructors in relation to Sumi's cultural, racial/ethnic, and linguistic backgrounds.

- Six informal interviews during the second semester of her practicum, which explored reflections on her professional grown as encountering challenges.

- One structured exit interview, which examined Sumi's final reflections on critical incidents, challenges, and professional growth.

Each interview was audio-recorded, with the participant's consent. Guided interviews include: (1) critical learning and challenging moments during teacher preparation, including her fieldwork, (2) challenges, if any, in relation to cultural, racial/ethnic and linguistic backgrounds, and her responses, and (3) reflections on her professional growth.

\subsection{Data Analysis}

I transcribed and analyzed Sumi's teaching observations, seminar observations and in/forma interviews and triangulated them with the field notes. Analysis was done with Microsoft Excel and the software program NVivo, which allowed coding categories to be added or changed as they emerge from the data. I looked for patterns of learning and challenging moments during Sumi's fieldwork, her responses to the challenges, and signs of her professional growth. I summarize my observations with field notes, focusing on (1) the participant's responses to challenges in relation to her cultural, linguistic, and racial backgrounds and (2) signs of her shifting perspectives and understandings on her challenges. I included extensive quotes from the formal and informal interviews in order to preserve the richness and detail of the original data with thick description (Geertz, 2003). This means several rounds of interpretative reading and categorizing of the themes. To describe clearly how Sumi responded to her challenges, interview data was analyzed to identify a general pattern of Sumi's reasoning and explanation about how she understood the challenges in teaching practice and interactions with her peers and fieldwork stakeholders. Finally, I analyzed the data to look for consistent themes to make sense of an overall story and counter-story. In order to have "engaged reflection and representation" of both Sumi's voices and those of the author, I reviewed the data repeatedly so that "one voice or narrative is not privileged over another" (Milner, 2007, p. 396).

\subsection{Researcher Role}

As a Korean female international graduate student and instructor, I had the advantage of being able to access and build rapport fairly quickly with my participant. My position as a cultural insider also allowed me to gain a better understanding of her experience. Nonetheless, I was cautious and careful not to impose or project my experiences on her while collecting or interpreting data. I tried constantly to examine my personal biases and prejudices to maintain the validity of the study. To prevent projecting my biases and experiences onto their views, I 
did not share my experiences in the U.S. with the participants. Further, to decrease my prejudices while interpreting the data, I shared my interview protocols, transcriptions, and findings with another Korean colleague.

While Nunan and Choi (2011) addressed the evolving aspect of story and "voice" in qualitative research, they pointed out that narrative inquiry is more than just telling stories or imposing meaning on these researched experiences. Rather, researchers need to draw insights and examine assumptions about the construction of narratives and phenomena such as identity and motivations. Thus, throughout this study, I often asked myself whose voice was represented, how, and why. As a form of member checking, I explained to my participant verbally and in a written form about the research purpose and procedure of this study, and I assured the confidentiality of the data.

\section{Findings}

Sumi revealed two main challenges in her professional development: (1) perceived professional incompetence due to perceived language proficiency, and (2) issues of adjustment to dominant communication and participation style in a U.S. academic context. Further, the findings demonstrates Sumi responded to her challenges in three ways: (1) internalization of assimilation narratives, (2) social exclusion and avoidance, and (3) resistance against perceived homogeneity.

\subsection{Challenges Faced by Sumi}

\subsubsection{Perceived Professional Incompetence due to Perceived Language Proficiency}

Sumi reported that she felt that her intelligence was ascribed to being a model minority, according to a racial stereotype of Asians (Lee, 2015). However, due to her perceived language proficiency, accents, and reserved participation in class, Sumi reported her own sense of insecurity with her accent as well as the assumption of incompetence from her peers. She described that her peers often ignored her presence during her coursework. She also shared her anxieties of public speaking during university classroom presentations, and her teaching practice during her practicum.

Whether the pain of being mocked and berated for her accents is real or imagined, its influence on lowering Sumi's sense of professional confidence seemed to be real. Also, Sumi appeared to experience the dismissive comments and questions from her elementary school students during her internship by their simply ignoring her presence or words, or sometimes explicitly stating, "I don't understand you." Not all linguicism is so overtly extreme, and yet those who speak English with accents are often met with a combination of unease, distrust, and irritation (Lippi-Green, 2012; Shuck, 2006). In a similar vein, Sumi reported that her perceived professional incompetence affected her self-esteem and confidence in her teaching practice during her fieldwork.

\subsubsection{Adjusting to Dominant Communication and Participation Style}

Not all students from Confucian-based education contexts, such as Korea, prefer to have lecture-based learning and teaching. At the same time, not all Western educational contexts 
favor discussion-oriented learning and teaching styles. However, communication between students and instructors can be challenging without intercultural understanding. When instructors and students in a Western host country set classroom norms, international Asian students often feel pressured to follow (DiAngelo, 2006). Further, those international students receive deficit-based views that can lead them to internalize feelings of deficiency (S. A. Kim \& R. H. Kim, 2010). Although Sumi went to an international high school in the Philippines where both teachers and students spoke English, she described her challenges with dominant learning environment in the U.S.:

Compared to the communication and learning styles in Philippines or Korea, U.S. teachers and students seem to prefer to be much direct and active in classroom. Teachers are supposed to act that way, as well.

Sumi illustrated the conflicts between who she should be in class (e.g. active and outspoken participant) and who she is (e.g. a quiet note-taker and good listener). She felt a great deal of pressure to assimilate to this classroom environment, and she felt inadequate to do so. She shared:

If you think about it, they [Americans] don't have to open up themselves to us. It's their country and they are rooted here. Why should they have to welcome and be open-minded just for me ... that's ridiculous. I used to think why people are not so nice to me and they don't want to get to know me, but you know what? It's very natural. They're born and raised here and they've been educated here. Why should they care about me, like a minority foreign person? I think I should've fought for being a similar position like them. Like trying to be similar like them. I couldn't do so. I am a failure in that way. I should have adjusted myself to their culture and assimilated. I couldn't do it. I will say to other Korean undergrads here that they should be more open about those adjustment and assimilation.

As illustrated, Sumi often expressed the pressure and her self-deficient identity of being unable to conform to a narrow standard of hegemonic student behaviors in order to succeed. While Sumi was very afraid of being misunderstood, she continued to be silent and isolated. She reported that:

I am a minority in this teacher preparation program. For a student like me, if there were anybody in terms of socializing or academic work, it might have been much better. You know, the only person who is willing to listen to me, that could have made my life different.

In Korean culture, students in the same class often become close friends, but she struggled to socialize with domestic pre-service teachers both in and outside the classroom.

\subsection{Sumi's Responses to Challenges}

\subsubsection{Internalizing “Assimilation” Narratives}

Acknowledging international students' cultural backgrounds and valuing their input in class can empower international students. However, Sumi spoke about a lack of support in 
incorporating her cultural and linguistic backgrounds during her practicum. Further, she reported that she found it difficult to offer alternative views on teacher education or elementary-level curriculum in the state, even when she wanted to share her own cultural backgrounds with her students:

It makes sense to focus on the U.S. for students. But it is a great pressure for me to adjust to the cultural norms and values. As an international student teacher, I should adjust and assimilate-things will be easier if I could do so.

Sumi talked about feeling limited by the curriculum that often focused on dominant North American values and ideals (e.g., freedom and democracy). Her mentor teacher also emphasized Sumi should know those fundamental values of America, rather than getting to know Sumi's cultural backgrounds and integrating them into her teaching practice.

Although Sumi could have contributed to expanding her students' knowledge and relate to students from diverse backgrounds, she appeared to be left with the message that "the American way is the right way" after doing her internship with her mentor teacher's ethnocentric views on curriculum and teaching. Sumi appeared to believe it is international students' responsibility to adjust culturally and linguistically, and assimilate into dominant North American cultures. She shared:

So I feel like everything is just half and half. I am very liberal compared to most Koreans, you know. So, in my mind, I feel like my identities are fighting too much. After these ten years of studying abroad in Philippines and the U.S, I feel very exhausted.

Sumi's experience is similar to that of many immigrant preservice teachers, "caught between the home and the American ways of doing things" (e.g., Palliotet, 1997). Sumi attributed to her isolation from other colleagues and peers to her lack of individual efforts.

\subsubsection{Social Exclusion and Avoidance}

While Sumi acknowledged that acculturation is an important process as international students, Sumi illustrated feeling socially and professionally isolated. Sumi reported having difficulty in understanding popular cultural references during casual conversations, jokes, slang, and other topics, during the breaks of the coursework in university. As a result, Sumi mainly associated with Korean students. Sumi explained her socialization with Koreans was her response to the underlying assumptions that all students do and will understand dominant North American culture and its idiosyncrasies in academic contexts or socializing settings. Those assumptions appeared to convey message to Sumi that she does not belong to either social, or professional spaces.

Sumi also shared that she performs different cultural identities while socializing with domestic peers, or Korean friends. For example, she reported that she is more chatty and lively with her Korean friends whereas being more silent with her domestic peers. As Sumi also avoids socialization with colleagues and peers during her fieldwork, she shared that she felt isolated. At the same time, she reported feeling being perceived as a cultural and linguistic outsider. 


\subsubsection{Resistance against Perceived Homogeneity}

Even though international Asian students are from different ethnic/racial, religious, and cultural backgrounds, those students often report being perceived as a homogeneous group (Poolokasingham et al., 2014). The term, "international students" and "Asians" includes several different cultures and lived experiences of students rather than being summed up into one homogeneous group that may be perceived as socio-culturally confused and alienated (Spencer-Rodgers, 2001; S. A. Kim \& R. H. Kim, 2010).

Sumi also shared her experiences of being often perceived to be Chinese who happened to be a dominant international student group in her college. She noted that this stereotypic view denies her cultural and individual differences. Further, she seemed to find it even insulting, due to her pride of being Korean and her feeling of superiority among other Asian ethnicities. Sumi wanted to identify herself solely as a Korean, not as an Asian or Asian international student. For example, she revealed her lateral racism against the Chinese international students:

Many Koreans don't have to start from ESL programs unlike lots of Chinese students. $\underline{W e}$ (Koreans) speak quite a good command of English. I think they (Chinese international students) come here to spend money. They put lots of efforts to decorate themselves, but still. I don't think they are fashionable at all. They wear all those design brands from the head to the toe. But it's so tacky. I don't like to see them spending serious money instead of studying. And you know Koreans, we think we are better than Chinese.

While I was not really sure how to respond to Sumi's remarks above, Sumi wanted to be affirmed that "we" as Koreans are superior to other Asian international students. In Sumi's attempt to maintain a distinctly Korean identity, she openly showed her lateral racism (Collins, 2016) towards "other" Asian international students. Sumi casually revealed her prejudice with the author that many Koreans hold. Koreans wish to distinguish themselves from other East Asians, such as Chinese or Japanese. This is, in part, based on a history in which Korea was often forced to pay tribute to China and was brutally colonized by Japan (Lee, 2015). The first author does not personally agree with Sumi's prejudice, but she does not deny this prejudice of Koreans against Chinese or Japanese. During the interview, Sumi knew the author is a Korean, a linguistic and cultural insider who appeared to share this sense of bias based on socio-historical and cultural backgrounds behind this view. Overall, Sumi expressed her strong resistance against homogeneous views towards Asians and showed forms of lateral racism against other East Asians.

\section{Discussion, Implications, and Limitation}

\subsection{Discussion}

Our findings are consistent with existing studies that document international students' challenges due to language barriers, invisibility, social exclusion and avoidance in classrooms and social settings, and consequently the pressure to fit in the dominant cultural and academic norms (e.g. Houshmand, Spanierman, \& Tafarodi, 2014). Given that Sumi described her teacher preparation contexts and professional settings as predominantly white, the notion of 
whiteness partly explains the pervasive phenomena of racialization. Whiteness is often enacted in classrooms to silence students of color. Whiteness is a set of practices that acts as a point of cultural reference and privileges one's social positionality (DiAngelo, 2007; Gomez, 2010). In higher education contexts, whiteness may position "them" (international Asian students) as quiet, passive learners, teacher-dependent with a lack of critical thinking, and users of rote learning style while "we" (dominant teacher educators in a western culture) and "our" (domestic, English-speaking) students are constructed as creative, critical, interactive, and active learners (Grimshaw, 2011; Ryan, 2011). Sumi's stories highlight the impact of internalizing the perceived deficit notions. For instance, Sumi often described herself as inadequate as a teacher despite her teacher preparation and certification in the U.S.

Further, this study expands discursive discourse about international student teachers in ways that moves beyond simplistic assumptions about "the international student" or "the Asian" as a homogeneous subject. For Sumi, it became more important to claim her individual and cultural heritage as a Korean. However, when Sumi internalized racial hiearchy and oppression, Sumi expressed her lateral racism towards other East Asian groups. Her response can be based on socio-historical relations among East Asian countries (Collins, 2016) as well as Sumi's socio-economic class (Lee, 2015). Lee's ethnographic study (2015) also noted that socio-economic class historically inhibited the development of the ethnic identity of Asians. Lee (ibid) pointed out the significance that class plays in how Korean-identified students define themselves and whom they define as the Other.

Sumi's racialized experiences help us relate to stories shared by language and ethnic/racial minority pre-service teachers who are marginalized and isolated. Many of those teacher candidates from diverse backgrounds report not fitting in the dominant or generally accepted notion of U.S. teachers such as those who speak English with accents (Soong, 2013). They also often felt pressured to assert their cultural and linguistic identities in a learning and professional context (Santoro, 2009).

\subsection{Implications}

It is significant for teacher educators to be aware of the marginalized position of international teacher candidates as well as complex social identities of those teacher candidates within East Asian groups. It is also important for teacher educators to encourage those linguistic and ethinc/racial minority teacher candidates to counter dominant discourses that perpetuate static and homogeneous notions of "Asian" international students.

Asian Americans are all too often portrayed as a model and a reticent minority (Lee, 2015), who fail to speak up for their rights, and fail to fight against racial discrimination. Solórzano et al. (2000) noted that, "[m]arginalized students are often familiar with their groups' voices being silenced in the classroom discourse or with having their personal and/or group experiences and beliefs discounted. These negative experiences occur in addition to the pervasiveness of the cultural deficit discourse in the academy" (see also, Valencia \& Solórzano, 1997). They argue not only for the importance of the counter-stories of students of color to challenge the dominant narratives and Whiteness on college campuses, but also emphasize the need of creating academic and social "counter-spaces" that "serve as sites 
where deficit notions of people of color can be challenged and where a positive collegiate racial climate can be established and maintained" (p. 70).

This article asserts that the experiences of Sumi in this study also demonstrate the significance of creating this counter-space as part of teacher preparation, in order to challenge the dominant discourse on international students. Teacher educators should not overlook possibly disempowering and silencing the international Asian preservice teachers by attributing the silence to their personality or cultural background. Furthermore, not only the intercultural awareness of the teacher educators, but also those of domestic pre-service teachers and fieldwork stakeholders (e.g., mentor teachers) should be promoted throughout the teacher preparation.

\subsection{Limitation}

Although I argue that this article created a counter-space for Sumi, I am aware that the short-term interviews and the limited number of the participant may not enough to represent the totality of East Asian preservice teachers' voices. Also, the participant's level of confidence and personality (e.g. Sumi with low confidence and shy personality) may impact the way they interact with others and also how they interpret their racialized experiences. Sumi's experiences may not represent the whole group of Koreans international students who choose to major education in an English speaking country. Nevertheless, our findings suggest that it is more significant to challenge the common assumptions about "us versus them" and learning ways of interacting with international students in teacher education contexts. Another limitation of this study is that the participants were exclusively female. Further research with a larger sample that includes various Asian international students' social identities (e.g. race/ethnicity, gender) may shed light on the relations within and across different international groups.

\section{Acknowledgements}

This research was supported by Summer Research Funding and Research Enhancement Grant by College of Education, Michigan State University.

\section{References}

Amin, N. (1997). Race and the identity of the nonnative ESL teacher. TESOL Quarterly, 31(3), 580-583. https://doi.org/10.2307/3587841

Aneja, G. A. (2016). (Non) native Speakered: Rethinking (Non) nativeness and Teacher Identity in TESOL Teacher Education. TESOL Quarterly, 50(3), 572-596. https://doi.org/ 10.1002/tesq.315

Campbell, J., \& Li, M. (2008). Asian students' voices: An empirical study of Asian students' learning experiences at a New Zealand university. Journal of Studies in International Education, 12(4), 375-396. https://doi.org/10.1177/1028315307299422

Canagarajah, A. S. (1999). Resisting linguistic imperialism in English teaching. Oxford: Oxford University Press. 


\section{Al Macrothink}

Journal of Educational Issues

ISSN 2377-2263

2017, Vol. 3, No. 1

Cole, A. L., \& Knowles, G. J. (2001). Lives in context: The art of life history research. Walnut Creek, CA.: AltaMira Press.

Collins, F. L. (2016). Migration, the Urban Periphery, and the Politics of Migrant Lives. Antipode, 48(5), 1167-1186. https://doi.org/10.1111/anti.12255

Delgado, R., \& Stefancic, J. (2012). Critical race theory: An introduction (2nd ed.). New York, NY: New York University Press.

DiAngelo, R. (2006). The production of whiteness in education: Asian international students in a college classroom. The Teachers College Record, 108(10), 1960-1982. https://doi.org/ 10.1111/j.1467-9620.2006.00771.x

Diniz de Figueiredo, E. H. (2011). Nonnative English-speaking teachers in the United States: issues of identity. Language and Education, 25(5), 419-432. https://doi.org/10.1080/09500 782.2011 .574702

Fries-Britt, S., George Mwangi, C. A., \& Peralta, A. M. (2014). Learning race in a US Context: An emergent framework on the perceptions of race among foreign-born students of color. Journal of Diversity in Higher Education, 7(1), 1. https://doi.org/10.1037/a0035636

Geertz, C. (2003). Thick description: Toward an interpretive theory of culture. Culture: Critical Concepts in Sociology, 1, 173-196.

Goodwin, A. L. (2010). Globalization and the preparation of quality teachers: Rethinking knowledge domains for teaching. Teaching Education, 21(1), 19-32. https://doi.org/10.1080/ 10476210903466901

Houshmand, S., Spanierman, L. B., \& Tafarodi, R. W. (2014). Excluded and avoided: Racial microaggressions targeting Asian international students in Canada. Cultural Diversity and Ethnic Minority Psychology, 20(3), 377. https://doi.org/10.1037/a0035404

Howard, T. C., \& Aleman, G. R. (2008). Teacher capacity for diverse learners: What do teachers need to know. Handbook of research on teacher education: Enduring questions in changing contexts (Vol. 3, pp. 157-174). New York, NY: Routledge.

Huber, L. P., \& Solórzano, D. G. (2015). Visualizing Everyday Racism Critical Race Theory, Visual Microaggressions, and the Historical Image of Mexican Banditry. Qualitative Inquiry, 21(3), 223-238. https://doi.org/10.1177/1077800414562899

Kim, S. A., \& Kim, R. H. (2010). Micro-aggressions experienced by international students attending US institutions of higher education. In Sue et al. (Ed.), Micro-aggressions and marginality: Manifestation, dynamics, and impact (1st ed., pp. 171-191). Hoboken, NJ, John Wiley \& Sons.

Kubota, R. (2015). Introduction: Race and language learning in multicultural Canada. Journal of Multilingual and Multicultural Development, 36(1), 1-2. https://doi.org/10.1080/ 01434632.2014 .892496

Kubota, R., \& Lin, A. (2006). Race and TESOL: Introduction to concepts and theories. Tesol 
Quarterly, 40(3), 471-493. https://doi.org/10.2307/40264540

Kubota, R., \& Lin, A. M. (Eds.). (2010). Race, culture, and identities in second language education: Exploring critically engaged practice. New York, NY: Routledge.

Lee, J. J., \& Rice, C. (2007). Welcome to America? International student perceptions of discrimination. Higher Education, 53(3), 381-409. https://doi.org/10.1007/s10734-0054508-3

Lee, S. J. (2015). Unraveling the "model minority" stereotype: Listening to Asian American youth. New York, NY: Teachers College Press.

Lippi-Green, R. (1997). English with an accent: Language, ideology, and discrimination in the United States. New York, NY: Psychology Press.

Ngo, B., \& Lee, S. J. (2007). Complicating the image of model minority success: A review of Southeast Asian American education. Review of Educational Research, 77(4), 415-453. https://doi.org/10.3102/0034654307309918

Pailliotet, A. W. (1997). I'm really quiet: A case study of an asian, language minority preservice teacher's experiences. Teaching and Teacher Education, 13(7), 675-690. https://doi.org/10.1016/S0742-051X(97)81484-9

Poolokasingham, G., Spanierman, L. B., Kleiman, S., \& Houshmand, S. (2014). "Fresh off the boat?" racial microaggressions that target South Asian Canadian students. Journal of Diversity in Higher Education, 7(3), 194. https://doi.org/10.1037/a0037285

Rosenwald, G. C., \& Ochberg, R. L. (Eds.). (1992). Storied lives: The cultural politics of self-understanding. London: Yale University Press.

Ryan, J. (2011). Teaching and learning for international students: Towards a transcultural approach. Teachers and Teaching, 17(6), 631-648. https://doi.org/10.1080/13540602.2011. 625138

Santoro, N. (2009). Teaching in culturally diverse contexts: What knowledge about "self" and "others" do teachers need? Journal of Education for Teaching, 35(1), 33-45. https://doi.org/10.1080/02607470802587111

Selvi, A. F. (2014). Myths and misconceptions about the nonnative English speakers in TESOL (NNEST) movement. TESOL Quarterly, 5(3), 573-611. https://doi.org/10.1002/ tesj. 158

Shuck, G. (2006). Racializing the nonnative English speaker. Journal of Language, Identity, and Education, 5, 259-276. https://doi.org/10.1207/s15327701jlie0504_1

Sleeter, C. E., \& Owuor, J. (2011). Research on the impact of teacher preparation to teach diverse students: The research we have and the research we need. Action in Teacher Education, 33(5-6), 524-536. https://doi.org/10.1080/01626620.2011.627045

Solórzano, D. G., \& Bernal, D. D. (2001). Examining transformational resistance through a 
critical race and LatCrit theory framework Chicana and Chicano students in an urban context. Urban Education, 36(3), 308-342. https://doi.org/10.1177/0042085901363002

Solórzano, D. G., Villalpando, O., \& Oseguera, L. (2005). Educational inequities and Latina/o undergraduate students in the United States: A critical race analysis of their educational progress. Journal of Hispanic Higher Education, 4(3), 272-294. https://doi.org/10.1177/ 1538192705276550

Solórzano, D., Ceja, M., \& Yosso, T. (2000). Critical race theory, racial microaggressions, and campus racial climate: The experiences of African American college students. Journal of Negro Education, 60-73. Retrieved from http://www.unco.edu/cebs/diversity/pdfs/crtmicroag gressions.pdf

Soong, H. (2013). Why volunteer? The complexities of international pre-service teachers' intercultural adjustment experiences through community service engagement. Asia-Pacific Journal of Teacher Education, 41(1), 69-83. https://doi.org/10.1080/1359866X.2012.75398

Spencer-Rodgers, J. (2001). Consensual and individual stereotypic beliefs about international students among American host nationals. International Journal of Intercultural Relations, 25(6), 639-657. https://doi.org/10.1016/S0147-1767(01)00029-3

Subedi, B. (2008). Contesting racialization: Asian immigrant teachers' critiques and claims of teacher authenticity. Race Ethnicity and Education, 11(1), 57-70. https://doi.org/10.1080/ 13613320701845814

Tran, L. T., \& Nguyen, N. T. (2015). Re-imagining teachers' identity and professionalism under the condition of international education. Teachers and Teaching, 21(8), 958-973. https://doi.org/10.1080/13540602.2015.1005866

Villegas, A. M., \& Lucas, T. (2002). Preparing culturally responsive teachers rethinking the curriculum. Journal of Teacher Education, 53(1), 20. https://doi.org/10.1177/0022487102 053001003

\section{Copyright Disclaimer}

Copyright for this article is retained by the author(s), with first publication rights granted to the journal.

This is an open-access article distributed under the terms and conditions of the Creative Commons Attribution license (http://creativecommons.org/licenses/by/3.0/). 